\title{
Executive functions deficits impair extinction of generalization of fear of movement-related pain
}

Citation for published version (APA):

Niederstrasser, N. G., Meulders, A., Meulders, M., Struyf, D., \& Vlaeyen, J. W. (2017). Executive functions deficits impair extinction of generalization of fear of movement-related pain. European Journal of Pain, 21(5), 886-899. https://doi.org/10.1002/ejp.991

Document status and date:

Published: 01/05/2017

DOI:

10.1002/ejp.991

Document Version:

Publisher's PDF, also known as Version of record

Document license:

Taverne

Please check the document version of this publication:

- A submitted manuscript is the version of the article upon submission and before peer-review. There can be important differences between the submitted version and the official published version of record.

People interested in the research are advised to contact the author for the final version of the publication, or visit the DOI to the publisher's website.

- The final author version and the galley proof are versions of the publication after peer review.

- The final published version features the final layout of the paper including the volume, issue and page numbers.

Link to publication

\footnotetext{
General rights rights.

- You may freely distribute the URL identifying the publication in the public portal. please follow below link for the End User Agreement:

www.umlib.nl/taverne-license

Take down policy

If you believe that this document breaches copyright please contact us at:

repository@maastrichtuniversity.nl

providing details and we will investigate your claim.
}

Copyright and moral rights for the publications made accessible in the public portal are retained by the authors and/or other copyright owners and it is a condition of accessing publications that users recognise and abide by the legal requirements associated with these

- Users may download and print one copy of any publication from the public portal for the purpose of private study or research.

- You may not further distribute the material or use it for any profit-making activity or commercial gain

If the publication is distributed under the terms of Article $25 \mathrm{fa}$ of the Dutch Copyright Act, indicated by the "Taverne" license above, 


\title{
Executive functions deficits impair extinction of generalization of fear of movement-related pain
}

\author{
N.G. Niederstrasser ${ }^{1,2,3}$, A. Meulders ${ }^{2,3}$, M. Meulders ${ }^{4,5}$, D. Struyf $f^{2,3}$, J.W. Vlaeyen ${ }^{2,3,6}$ \\ 1 School of Sport, Exercise and Health Sciences, Loughborough University, UK \\ 2 Research Group Health Psychology, KU Leuven, Belgium \\ 3 Center for Excellence on Generalization Research in Health and Psychopathology, KU Leuven, Belgium \\ 4 Center for Information Management, Modeling and Simulation, KU Leuven, Belgium \\ 5 Research group on Quantitative Psychology and Individual Differences, KU Leuven, Belgium \\ 6 Department of Clinical Psychological Science, Maastricht University, The Netherlands
}

Correspondence

Nils Georg Niederstrasser

E-mail: n.g.niederstrasser@|boro.ac.uk

\section{Funding sources}

The contribution of Nils Georg Niederstrasser was supported by the Center of Excellence on Generalization Research (GRIP*TT; University of Leuven grant PF/10/ 005). Ann Meulders is a postdoctoral researcher of the Research Foundation Flanders (FWO-Vlaanderen), Belgium, (grant ID: $12 \mathrm{E} 3714 \mathrm{~N})$. Part of these data was presented in the symposium on 'LEARNING PAIN-RELATED FEAR: NEURAL MECHANISMS, GENERALIZATION AND EXTINCTION' at the $9^{\text {th }}$ EFIC $^{\circledR}$ Congress, PAIN IN EUROPE IX, Vienna, Austria, September 2015. Johan Vlaeyen is supported by the Odysseus Grant, 'The Psychology of Pain and Disability Research Program' funded by the Research Foundation Flanders (FWO-Vlaanderen), Belgium, as well as the 'Asthenes' long-term structural funding-Methusalem grant by the Flemish Government, Belgium.

\section{Conflicts of interest}

None declared.

\section{Accepted for publication}

8 November 2016

doi:10.1002/ejp.991

\section{Abstract}

Background: Generalization of fear of movement-related pain across novel but similar movements can lead to fear responses to movements that are actually not associated with pain. The peak-shift effect describes a phenomenon whereby particular novel movements elicit even greater fear responses than the original pain-provoking movement (CS+), because they represent a more extreme version of the CS+. There is great variance in the propensity to generalize as well as the speed of extinction learning when these novel movements are not followed by pain. It can be argued that this variance may be associated with executive function capacity, as individuals may be unable to intentionally inhibit fear responses. This study examined whether executive function capacity contributes to generalization and extinction of generalization as well as peak-shift of conditioned fear of movementrelated pain and expectancy.

Methods: Healthy participants performed a proprioceptive fear conditioning task. Executive function tests assessing updating, switching, and inhibition were used to predict changes in (extinction of) fear of movement-related pain and pain expectancy generalization.

Results: Low inhibitory capacity was associated with slower extinction of generalized fear of movement-related pain and pain expectancy. Evidence was found in favor of an area-shift, rather than a peak-shift effect, which implies that the peak conditioned fear response extended to, but did not shift to a novel stimulus.

Conclusions: Participants with low inhibitory capacity may have difficulties withholding fear responses, leading to a slower decrease of generalized fear over time. The findings may be relevant to inform treatments.

Significance: Low inhibitory capacity is not associated with slower generalization, but extinction of fear generalization. Fear elicited by a novel safe movement, situated outside the CS+/- continuum on the CS+ side, can be as strong as to the original stimulus predicting the pain-onset. 


\section{Introduction}

As a movement is repeatedly followed by pain, individuals learn to expect pain during that movement. A cue for pain, the movement may elicit an anticipatory fear response before it is performed, hence, fear of movement-related pain (Vlaeyen et al., 1995). Conversely, movements expected to be pain-free do not elicit fear (Meulders et al., 2011).

Certain novel movements, unfamiliar in their pain-eliciting properties, can also elicit fear responses, because they resemble previously encountered painful movements, called stimulus generalization (Ghirlanda and Enquist, 2003). Generalization is adaptive; it allows individuals to successfully avoid pain in similar situations, but becomes dysfunctional when fear spreads to pain-free movements. The resemblance between painful and novel movements determines the strength of the generalized fear response, which generally peaks at the pain-provoking movement (Honig and Urcuioli, 1981; McLaren and Mackintosh, 2002; Meulders et al., 2013).

Conditioning theory, however, suggests that the peak of the fear response can shift from a painful movement to a novel movement, known as peak-shift effect. This may happen, because the novel movement bears the excitatory properties associated with pain to an even greater degree (Blough, 1975; Pearce, 1987; McLaren and Mackintosh, 2002; Struyf et al., 2014). For example, post-accident, an individual experiences that standing up straight feels fine, while bending over slightly is painful and fear-eliciting; being asked to pick up a parcel, hence bending more deeply, may elicit even greater fear. Alternatively, extension of the peak fear response to include, rather than shift, to the novel movement is known as area-shift.

When a novel movement is performed that is expected to provoke pain but does not, the fear response decreases and eventually extinguishes over repeated pain-free performances, known as extinction of fear generalization (Vervliet et al., 2013). Since the expected outcome of pain does not occur, the belief that the movement induces pain is disconfirmed and requires revision. The rate at which expectations of outcomes are revised varies between individuals and might be influenced by individuals' executive function capacity.

Executive function capacity refers to the ability to inhibit dominant, prepotent, or automatic responses when necessary, update information in changing environments, and switch from irrelevant towards relevant information (Miyake et al., 2000). Low executive function capacity might delay extinction, because individuals are slower to form novel inhibitory associations (movement not followed by pain) blocking the expression of excitatory associations (movement followed by pain) (Rao et al., 1987). Such excitatory associations prompt automatic fear responses, which are difficult to withhold intentionally (Miyake et al., 2000). Difficulty to inhibit fear responses might hamper extinction learning and cause greater fear to novel movements. This is supported by evidence suggesting that highly fearful individuals (Lissek et al., 2005) and chronic pain patients (Meulders et al., 2015) fail to inhibit physiological and self-reported fear to novel stimuli. Low updating or switching capacities might precipitate a reluctance to revise presumptive associations between movements and pain or shift to a new rule, as required during extinction, possibly decelerating extinction of generalization. In fact, Lenaert and colleagues (Lenaert et al., 2016), using a visuospatial working memory task, showed negative correlations between blocking irrelevant information from entering working memory, essentially updating, and generalization.

The current study with healthy volunteers addressed three questions: (1) Do participants with low executive function capacity display greater fear responses to novel stimuli, (2) slower extinction of generalized fear responses, and (3) is there a peakshift in fear responses away from the original painprovoking towards a novel movement?

\section{Methods}

\subsection{Participants}

We used a convenience sample including 48 healthy participants $\left(32\right.$ females, $\quad M_{\text {age }}=21.71$ years, $\mathrm{SD}_{\text {age }}=2.62$, ranging from 18 to 33 years). Participants were recruited through advertisements distributed around the KU Leuven campus or by means of the departmental experiment management system (EMS; SonaSystems Ltd., Talinn, Estonia). A standardized health checklist was used to screen participants for the exclusion criteria. Individuals were not considered for participation if they (1) suffered from a chronic pain condition (2) suffered from a cardiovascular disease, neurological disease, musculoskeletal disorder, or psychiatric disorder (3) were pregnant at the time (4) had been implanted a cardiac pacemaker or other electronic medical devices (5) had any kind of uncorrected hearing problems (6) were under 18 years of age (7) had recently used analgesic, anxiolytic, or anti-depressant medication, or (8) had any injuries to or acute pain at the 
dominant wrist or hand. Prior to commencing the study, ethical clearance was received from the Ethical Committee of the Faculty of Psychology and Educational Sciences of the KU Leuven (registration number: S56135) and the Medical Ethical Committee of KU Leuven University Hospital (registration number: ML10016). Participants were informed that they could withdraw from the study at any given time without any consequences. The data of three participants were excluded from analyses due to equipment malfunctions; the statistical analyses were carried out on a total sample of 45 participants.

\subsection{Nomenclature}

Throughout the following sections, we will use acronyms to refer to certain movements, stimuli, and responses in order to increase brevity and readability of the manuscript. Supporting Information Table S1 provides an overview of the used nomenclature. An unconditioned stimulus (US), is any stimulus that elicits an unconditioned response (UR; e.g. fear response), without necessitating any prior learning, such as a painful stimulus. If another stimulus, such as a movement, is repeatedly paired with a US (e.g. pain), it becomes predictive of the US and is referred to as conditioned stimulus (CS), because the onset of the US is conditional on the presence of the CS. After repeated pairings of the conditioned stimulus (movement) with the pain-US, the CS on its own starts to elicit a similar response (e.g. fear) as the US, because it is predictive of its onset. In this case the response to the CS, which is the same as to the US (e.g. fear), is referred to as conditioned response (CR). In certain cases more precise nomenclature is necessary to describe the exact predictive properties of specific conditioned stimuli. If a proprioceptive CS (e.g. during movement) predicts the onset of the US (e.g. pain), it is referred to as CS+, while another proprioceptive CS (e.g. during another movement) that predicts the absence of the US is referred to as CS-. Naturally, the CS+ is more likely to elicit a CR (e.g. fear response) than the CS-, because it is predictive of the onset of the US (e.g. pain) (Pavlov and Anrep, 1927; Rescorla, 1969). A generalization stimulus (GS) is a stimulus that is similar to the CS+ and the CS-, and depending on the degree of resemblance, individuals might expect the onset of the US (e.g. pain) with the GS, which may lead to a CR (e.g. fear) in response to the GS. Consider an example, bending at the hip at 45 degrees (CS+) is painful (US) and therefore elicits fear, upon prompting to bend over (CR). Standing up straight is not painful
(CS-) and therefore does not elicit a fear response (see Supporting Information Fig. S1).

\subsection{Procedure}

Upon arrival, each participant provided informed consent, followed by completion of the Pain Catastrophizing Scale (Sullivan et al., 1995) and the Fear of Pain Questionnaire-III (McNeil and Rainwater, 1998). Participants were informed that painful electrocutaneous stimuli (pain-USs) would be administered during the experiment, before the electrodes for the pain-US were attached. Next, participants completed a proprioceptive fear conditioning task modeled after Meulders and colleagues (Meulders et al., 2011, 2013), divided into 5 phases, followed by 3 computerized tasks to assess executive function capacity. Note that the experimental procedure also included the placement of three facial electrodes and the presentation of auditory startle probes related to the measurement of fear-potentiated eyeblink startle. ${ }^{1}$

\subsubsection{Stimulus material}

A semi-circle was divided into 7 equally spaced quadrants aimed to create the proprioceptive CSs. All stimuli (CSs, PSs, and GSs) consisted of moving a Paccus Hawk joystick, (Paccus Interfaces BV, Almere, The Netherlands) with the dominant hand into one of the 7 movement quadrants (see Fig. 1). Movements into quadrants 2 and 6 (from the left to the right) were randomly assigned to serve as the $\mathrm{CS}+\mathrm{l}-$. Based on the CS+/- randomization, movements into quadrants 1 or 7 served as the peak-shift stimuli (PS+/-). The PS+ was situated outside the CS+/continuum on the CS+ side, while the PS- was positioned outside the continuum on the CS- side. Movements into quadrants 3 through 5 served as the generalization stimuli (GSs). The unconditioned stimulus (pain-US) was a $2 \mathrm{~ms}$ electrocutaneous stimulus, generated by a commercial constant current stimulator (DS5 Digitimer, Welwyn Garden City, UK). Two surface SensorMedics (Homestead, FL, USA; $8 \mathrm{~mm}$ diameter) electrodes were used to deliver electrical stimulation to the dorsal surface of the wrist of participants' dominant hand. The electrodes were spaced approximately $1 \mathrm{~cm}$ apart and filled with K-Y gel (Johnson \& Johnson, New Brunswick, NJ, USA). Prior to commencing the experimental procedure, the intensity of the pain-US was individually calibrated. The experimenter started with an intensity of $1 \mathrm{~mA}$ and gradually increased the stimulus intensity in steps of $4 \mathrm{~mA}$ until participants reported experiencing the stimulus as 

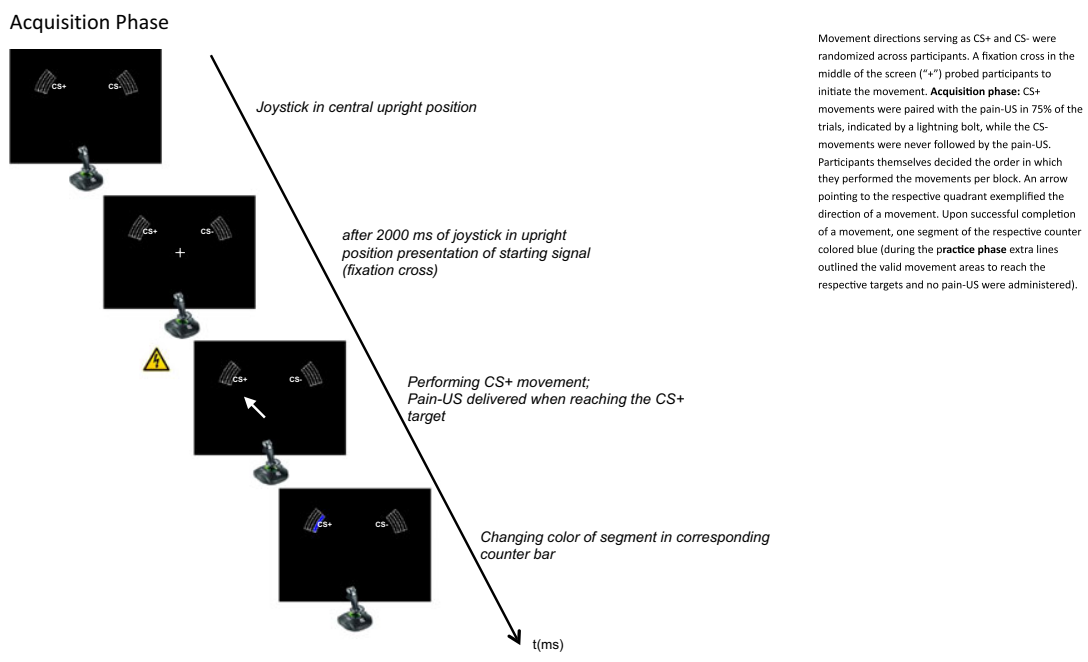

Generalization Phase

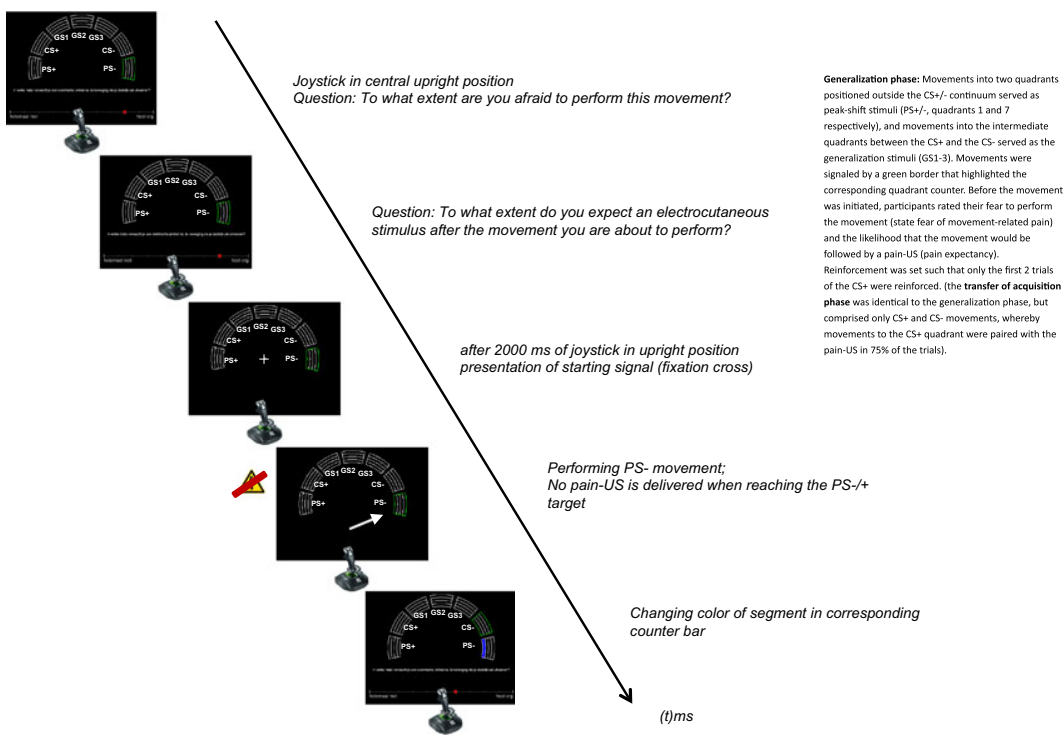

Figure 1 Overview of experimental joystick-conditioning task during the acquisition and generalization phases

'significantly painful and demanding some effort to tolerate'. Participants verbally rated their pain intensity on a numerical rating scale (NRS) from 0 to 10 , with 0 'no pain' and 10 'maximally tolerable pain'. For reference purposes the NRS was placed on the wall facing the participants; a rating of 8 on the NRS was targeted to serve as the pain-US. The average current administered was $65.2 \mathrm{~mA} \quad(\mathrm{SD}=25.72$, range 19-100 $\mathrm{mA}$ ). All participants rated the selected pain intensity as 8 on a 0 to 10 NRS.

\subsubsection{Practice phase}

Participants were given oral and written instructions at the beginning of the conditioning task. During the practice phase, participants were only shown quadrants 2 and 6 of the semi-circle. Participants were instructed to move the joystick towards counters, which were positioned at the outer borders of quadrants 2 and 6 (see Fig. 1, upper panel). The purpose of the practice phase was to give participants the opportunity to learn what constitutes a correct movement within this experimental task. For that purpose, extra lines outlined the valid movement area to reach the respective counters. The counter was a rectangular shape divided into 4 equal segments, situated on top of the outer edge of the corresponding movement quadrant. Upon completion of a correct movement, one segment of the 
corresponding counter colored blue. The segments did not change color upon incorrect movements. The practice phase consisted of 2 blocks of 8 trials. In the beginning of each trial participants moved the on-screen cursor towards the middle of the screen using the joystick. This location reflected the central upright position of the joystick. Once the cursor had been positioned in the middle of the screen for $2 \mathrm{~s}$, it disappeared. Two seconds later, a fixation cross $(+)$ appeared in the middle of the screen, indicating that the movement could be initiated. After successful completion of the movement, the cursor reappeared. Participants were provided with online feedback by the experimenter, and they also received error messages on the screen when they did not perform the task correctly. Upon leaving the valid movement area, an error message ('incorrect movement') appeared and the movement was repeated. After completion of 16 correct trials participants automatically moved on to the next phase.

\subsubsection{Acquisition phase}

The acquisition phase was similar to the practice phase, except that (1) the pain-US was delivered following movements to the quadrant designated as the CS+ in $75 \%$ of the trials, (2) no extra lines outlining the valid movement area were shown, and (3) no error messages were displayed upon invalid movements. Participants were free in deciding the order in which they performed the movements per block. Invalid movements had to be repeated and were indicated by the counter on top of the corresponding quadrant not changing color.

The acquisition phase consisted of 3 blocks of 8 trials, of which an equal number were to the CS+/quadrant per block. One of the movement quadrants, 2 or 6, was randomly chosen as CS + /-. Movements to the CS+ quadrant were paired with the pain-US in $75 \%$ of the trials, while the CS- was never followed by the pain-US. Although the duration of the CS movement itself was of variable length depending on participants' response latencies and movement speed, there was a fixed interval of $6 \mathrm{~s}$ between trials.

\subsubsection{Transfer of acquisition phase}

The purpose of the transfer of acquisition phase was to ensure the transfer of the previously acquired $\mathrm{CS}+/-$ contingencies to a novel context (e.g., movements were directed, rather than chosen by participant). The phase also served to preclude confusion among participants regarding a change in instructions before starting the generalization phase. The phase was identical to the acquisition phase with the exception that participants were not free in choosing the sequence in which they completed the movements and it was limited to one block of eight trials. The quadrant to which they had to move was highlighted by means of a green border around the respective counter (see Fig. 1, lower panel). While the counter was highlighted and before the movement was initiated, participants rated their fear to perform the movement on an on-screen 11-point NRS from 0 to 10 , with 0 'not at all' and 10 'very much?' ('To what extent are you afraid to perform this movement?'). Next, participants rated their expectation that the movement would be followed by a pain-US from 0 to 10 , with 0 'not at all' and 10 'very much' ('To what extent do you expect an electrocutaneous stimulus after the movement you are about to perform?'). The sequence of the CS+/- was quasi-randomized with the restriction of an equal number of movements towards the CS+ and CSper block and such that no movement was performed more than twice consecutively.

\subsubsection{Generalization phase}

In order to assess the generalization of conditioned fear of movement-related pain and pain expectancy, participants were prompted to complete movements to the 5, previously omitted, quadrants as well as to the original $2 \mathrm{CS}+/-$ quadrants. The generalization phase consisted of 4 trials of each of the 7 movements in a semi-randomized order. Randomization was set such that 2 trials to each quadrant had to be completed, before the last 2 trials could be completed. The first $2 \mathrm{CS}+$ trials were always paired with the pain-US, while during the third and fourth trials the movements were no longer reinforced. None of the GS movements were followed by the pain-US.

\subsubsection{Hardware and software}

The experiment was run on a Dell Opti-Plex Windows XP machine equipped with 2 GB RAM and an Intel Core2 Duo processor. Connected to the computer was a 15-inch screen, used to display the experiment. Data acquisition and stimulus presentation were controlled using the free software package Affect 4.0 (Spruyt et al., 2010) and the data were recorded using a National Instruments data acquisition card. 


\subsubsection{Affective valence/arousal/control}

As a manipulation check and following completion of the conditioning task, a computerized version of the Self-Assessment Manikin (SAM) (Bradley and Lang, 1994) scale was completed. The SAM comprises 5 pictographs that show a figure ranging from smiling, happy to frowning, unhappy. Scores on the SAM are used to examine affective valence of the respective CS movements with scores ranging from 1 'very happy' to 5 'very unhappy'. Similar pictographs were used to assess participants' sense of control and arousal. The scales were completed for both CS movements respectively at the end of the practice phase, acquisition phase, and generalization phase.

\subsubsection{Pain intensity ratings}

Intensity of the pain-US was assessed following each block of the acquisition phase, the transfer of acquisition phase, and the generalization phase. Participants indicated the perceived pain intensity on a computerized NRS from 0 to 10 , with 0 'no pain' and 10 'maximally tolerable pain'.

\subsubsection{Executive function tasks}

The stop-signal task (Vince, 1948; Lappin and Eriksen, 1966; Verbruggen and Logan, 2008) was used to measure individuals' inhibitory capacity. On this task, participants were requested to deliberately stop a response that is relatively automatic. The task consisted of 6 blocks comprising 32 trials each. Participants were requested to respond to a cross or circle, pressing the ' $\%$ ' or ' $\mathrm{z}$ ' button on the keyboard (qwerty-type) depending on which shape was presented. Stickers with ' $\mathrm{x}$ ' and ' $\mathrm{o}$ ' printed on them were attached to the keyboard buttons such that the ' $\mathrm{z}$ ' button represented an ' $\mathrm{x}$ ' and was pressed when the cross shape appeared, while the ' $\%$ ' button represented a ' $\mathrm{O}$ ' and was pressed when the circle appeared. Participants were instructed to respond as fast as possible (before $1500 \mathrm{~ms}$ ). The first block was used to build up an automatic categorization response to both shapes and was not included in the statistical analysis. In $25 \%$ of trials (24 for each shape), the categorization response had to be inhibited when participants heard a computer-emitted tone. In the beginning of the task, the tone was emitted $250 \mathrm{~ms}$ following the display of the shape. This delay increased by $50 \mathrm{~ms}$ when the response was successfully inhibited and decreased by $50 \mathrm{~ms}$ when the response was not inhibited. The outcome variable for this task was the stop signal reaction time (SSRT). The latter was computed by subtracting the mean reaction time on go trials from the averaged stop signal delay. A longer SSRT is indicative of lower response inhibitory capacity.

The Wisconsin card sorting test (WCST) (Grant and Berg, 1948) was used to measure switching capacity (Miyake et al., 2000). In this test, participants were provided with a set of cards that they were requested to sort according to abstract rules corresponding to specific stimulus attributes (i.e. color, form, number). After 10 sequential correct trials, the rule switched and participants, based upon validating/invalidating feedback, were requested to switch to sorting according to a different stimulus characteristic. In the current experiment we used a computerized version of the WCST modeled after Grant and Berg (Grant and Berg, 1948) containing 2 decks of 64 cards. The percentage of perseverative responses, that is, the proportion of attempts to continue sorting to an obsolete rule after the reference category had changed, was used as an indicator of switching capacity. Therefore, a lower score on the WCST is indicative of higher switching capacity.

The operation span task, modeled after Turner and Engle (Turner and Engle, 1989), was used to measure updating capacity (Miyake et al., 2000). During the task, participants solved simple math equations while memorizing letters. Participants received equation-letter pairs on the computer screen. For each pair there was one equation (e.g. $3 \times 4=12$; or $2 \times 7=19$ ), which had to be answered with 'true' or 'false', while a letter was presented. At the end of the trial, participants were asked to recall all letters from the entire set of equation-letter pairs in the same order as it was given to them. A greater score on the operation span task indicates higher updating capacity.

\subsection{Data analysis overview}

Descriptive statistics were computed on sample characteristics and scores on the executive function facets (e.g. updating, inhibition, and switching). Multilevel regression models were used to examine differential fear learning, (extinction of) generalization, as well as the presence and extinction of peak-shift for both conditioned fear of movement-related pain and pain expectancy.

The hypotheses formulated for fear of movementrelated pain apply also to pain expectancy. Pain expectancy is a valuable measure of conditioned responding and a proxy of fear learning, as it reflects 
an individual's belief in the occurrence of pain (Boddez et al., 2013).

Both fear of movement-related pain and pain expectancy are conditioned responses and referred to as ' $C R$ ' in the remainder of this section to increase readability. Note that differential learning was examined as a manipulation check for conditioned fear of movement-related pain only, as pain expectancy was not measured during acquisition. Differential acquisition of fear of movement-related pain was found to be achieved. Details of the analysis can be found in the Supporting Information.

We investigated the three hypotheses: Hypothesis 1: the lower the executive function capacity (updating, switching or inhibition) the stronger the conditioned fear of movement-related pain and pain expectancy generalization. We examined whether the rate of change in the magnitudes of the CRs to the GSs, situated within the CS+/- continuum (e.g. CS+, GS1, GS2, GS3, and CS-) differed as a function of scores on one of the executive function facets. Interactions between the rate of change of the $\mathrm{CR}$ over the $\mathrm{CS}+/$ - continuum and scores on at least one of the executive function facets are indicative of varying gradient shapes, suggesting differences in generalization and supporting hypothesis 1. Hereby, steeper gradients are indicative of less generalization. Upon significant interactions, follow-up analyses are performed to determine whether gradients are flatter for individuals scoring low as compared to individuals scoring high on executive function capacity.

Hypothesis 2: the higher the executive function capacity the stronger the extinction of conditioned fear of movement-related pain and pain expectancy generalization. The second hypothesis was investigated by examining if one of the executive function aspects predicted the change in fear of movement-related pain or pain expectancy over trials. Slower extinction of the CRs to the GSs is indicated when the CRs to the GSs during the generalization phase change over trials at a slower rate. Tests examining the interaction between the change in CRs over trials and scores on the executive function facets determined whether there were differences in extinction of the CRs as a function of scores on the executive function facets. Interactions between a score on one of the executive function tests and the change over trials (trials 1-4) would support hypothesis 2 .

Lastly, hypothesis 3: the lower the executive function capacity, the stronger the shift of the peak fear response and pain expectancy judgment from the CS+ to the PS+. Evidence in favor of a peak-shift is indicated by significantly greater CRs in response to the PS+ compared to the CS + and the GSI (e.g. PS $+>\mathrm{CS}+>\mathrm{GS} 1$ ), supporting hypothesis 3. Hence, testing for peak-shift involves two stages (e.g. PS+ vs. CS + and PS + vs. GS1). Testing for area-shift comprises the identical contrasts, but is indicated by different outcomes (e.g. PS $+=$ CS $+>$ GS1). As peak-shift and area-shift are tested using identical contrasts, we have sufficient power to test for the presence of both. To test the peak-shift away from the CS+ we limited the examination of the data to the first trial of the generalization phase. Peak-shift is believed to be the result of generalization of excitatory properties of the CS+. Previous research has shown that this type of generalization is strongest during the first trial of the generalization phase (Dunsmoor et al., 2009; Meulders et al., 2013). Due to extinction effects, CRs are likely to decrease over repeated unreinforced trials for the PS+. It is therefore reasonable to expect a peak-shift only during the first trial of the generalization phase.

Pain-related fear responses and expectancy judgments for the PS - were collected as well, but not analyzed and reported in the absence of a priori hypotheses and the prediction that responses lower than to the CS- are unlikely to be observed, rendering a negative peak-shift effect implausible (Ghirlanda and Enquist, 2003).

Kolmogorov-Smirnov tests of normality were executed to assess the distribution of the data. The tests revealed that scores on the SSRT were significantly non-normal $(D(45)=0.16, p<0.05)$. A logarithmic transformation was used to establish normality. After the transformation, the scores on the SSRT did not deviate from the normal distribution anymore $(D$ $(45)=0.12, p=0.14)$. Analyses were carried out on the transformed SSRT scores.

The multilevel regression models for predicting CRs (conditioned fear of movement-related pain responses and pain expectancies respectively) can be found in the Supporting Information. The effects included in each model were estimated simultaneously using the SAS (Cary, NC, USA) procedure MIXED (Verbeke and Molenberghs, 2000).

\section{Results}

\subsection{Sample characteristics}

Supporting Information Table S2 shows the descriptive statistics for characteristics related to the sample and the pain-US. Supporting Information Table S3 presents the correlations between the executive function facets. Updating and switching capacities were significantly correlated with the selected pain-US 
intensity (in mA) during the calibration phase. Supporting Information Table S4 presents an overview of the number of participants scoring within a certain range of the executive function facets. Participants scoring at least 2 standard deviations above the mean were considered high responders, while participants scoring at least 2 standard deviations below the mean were labeled low responders.

\subsection{Hypothesis}

The lower the executive function capacity (updating, switching or inhibition) the stronger the conditioned fear of movement-related pain and pain expectancy generalization (Model 2).

Multilevel regression analyses were conducted to examine the contribution of executive function capacity to the prediction of conditioned fear of movement-related pain ratings and pain expectancy judgments during trial 1 of the generalization task. In other words, generalization effects were evaluated on trial 1, while changes over trials 1-4 were used to evaluate extinction of generalization (separate analysis). Furthermore, the multilevel regression analyses assumed a linear change in the magnitudes of the CRs from the CS+ over the GSs (e.g. GS1-3) to the CS - for trial 1. There were no significant interactions between switching, updating, or inhibition and the linear change of neither fear of movement-related pain ratings nor pain expectancy judgments (see Supporting Information Tables S5 and S6). The findings imply that there was a generalization gradient for both dependent measures, but that the shapes of the generalization of fear of movement-related pain and pain expectancy gradients did not differ as a function of participants' executive function capacity (e.g. switching, updating, or inhibition).

Hypothesis 2. The higher the executive function capacity the stronger the extinction of conditioned fear of movement-related pain and pain expectancy generalization (Model 3).

Next, we examined the relationship between the rate of extinction of fear generalization as well as pain expectancy judgments with executive function capacity. All models (see Tables 1 and 2; Supporting Information Tables S7-S10) assume that the magnitude of the fear ratings and pain expectancy judgments to a specific stimulus (e.g. stimulus type: CS+, GS1, GS2, GS3, CS-) changed linearly over the four trials and that the slope of the linear change depended on the respective executive function facet. Thus, the slopes for each stimulus type represented the rate of extinction for that particular stimulus type over 4 trials. In order to increase statistical power of the models, we constrained the models further, such that for each facet of executive function all interactions between stimulus type and the specific executive function facet (e.g. inhibition, switching, and updating) were equal.

The multilevel regression analysis revealed a significant interaction between the linear rate of extinction for conditioned fear of movement-related pain and inhibitory capacity (see Fig. 2). The interaction effect indicates that the slope of the linear trend for the change in the magnitude of the fear response to the specified stimuli (CS+, GS1, GS2, GS3, CS-) varied as a function of inhibitory capacity $\left(\beta_{\text {Txinhib }}=0.08\right.$, $\mathrm{SE}=0.04, p<0.05$; see Table 1). Further analyses revealed that the slope of the linear trend for change in fear response magnitudes was steeper for individuals with high inhibitory capacity, as compared to low inhibitory capacity (difference slope high vs. low inhibitory capacity: $\quad-4 \beta_{\text {Txinhib }}=-0.32, \quad \mathrm{SE}=0.15$, $p<0.05)$. Similar results pertaining to the interaction between inhibitory capacity and the extinction of pain expectancy judgments were found $\left(\beta_{\text {Txinhib }}=0.11\right.$, $\mathrm{SE}=0.05, p<0.05$; see Table 2 ). Thus, the change in pain expectancy ratings differed as a function of participants' inhibitory capacity. Analogous to the previous findings, individuals with high inhibitory capacity revealed a steeper slope compared to individuals with low inhibitory capacity (difference slope high vs. low inhibitory capacity: $-4 \beta_{\text {Txinhib }}=-0.43, \mathrm{SE}=0.18$, $p<0.05)$. Steeper slopes, as found among participants with high inhibitory capacity, are indicative of faster extinction.

In sum, participants with high inhibitory capacity decreased in their fear and pain expectancy judgments over repeated trials in response to the same stimuli more quickly than participants with low inhibitory capacity. Please note that these models explain the data fairly well, accounting for $83 \%$ (fear responses) and $81 \%$ (pain expectancy judgments) of the variance in the observed responses.

There were no interactions between the linear trend of the change in fear responses or pain expectancy judgments associated with the stimuli over trials and scores on the remaining executive function facets (see Supporting Information Tables S7-S10), which indicates that the rates of extinction did not differ as a function of scores on any of the remaining executive function facets.

Hypothesis 3. The lower the executive function capacity, the stronger the shift of the peak fear response and pain expectancy judgment from the CS+ to the PS+ (Model 4). 
Table 1 (Model 3) Multilevel regression predicting the extinction of fear responses to each stimulus and its association with inhibitory capacity.

\begin{tabular}{|c|c|c|c|c|c|c|c|}
\hline Effect & Description & & CS+ & GS1 & GS2 & GS3 & CS- \\
\hline \multirow[t]{3}{*}{$\mu$} & \multirow{3}{*}{$\begin{array}{l}\text { Estimated intercept of the linear trend (i.e. at } T=0 \text { ) per stimulus } \\
\text { for subjects with average levels of inhibition and with an } \\
\text { average random intercept value }\end{array}$} & Estimate & 6.38 & 5.10 & 3.54 & 2.74 & 2.48 \\
\hline & & SE & 0.39 & 0.31 & 0.27 & 0.25 & 0.26 \\
\hline & & $p$-value & $<0.001$ & $<0.001$ & $<0.001$ & $<0.001$ & $<0.001$ \\
\hline \multirow[t]{3}{*}{$\beta_{\mathrm{T}}$} & \multirow{3}{*}{$\begin{array}{l}\text { Slope of the linear trend per stimulus for subjects with an average } \\
\text { inhibition score (i.e. } z_{i}^{\text {inhib }}=0 \text { ) }\end{array}$} & Estimate & -0.05 & -1.10 & -0.87 & -0.61 & -0.53 \\
\hline & & SE & 0.08 & 0.08 & 0.08 & 0.08 & 0.08 \\
\hline & & $p$-value & 0.56 & $<0.001$ & $<0.001$ & $<0.001$ & $<0.001$ \\
\hline \multirow[t]{3}{*}{$\beta_{\text {inhib }}$} & \multirow{3}{*}{$\begin{array}{l}\text { Increase in the intercept of the linear trend (i.e. at } T=0 \text { ) per } \\
\text { stimulus, due to an increase of one SD for the inhibition score }\end{array}$} & Estimate & 0.21 & 0.07 & 0.001 & -0.11 & -0.21 \\
\hline & & SE & 0.38 & 0.29 & 0.25 & 0.23 & 0.23 \\
\hline & & $p$-value & 0.59 & 0.80 & 10.00 & 0.64 & 0.36 \\
\hline \multirow[t]{3}{*}{$\beta_{\text {Txinhib }}$} & \multirow{3}{*}{$\begin{array}{l}\text { Interaction effect between the linear trend per stimulus and the } \\
\text { standardized inhibition score. This effect represents the change } \\
\text { in the slope of the linear trend if } Z_{i}^{\text {inhib increases one standard }} \\
\text { deviation (note: interactions are constrained to be equal across } \\
\text { stimuli) }\end{array}$} & Estimate & 0.08 & 0.08 & 0.08 & 0.08 & 0.08 \\
\hline & & SE & 0.04 & 0.04 & 0.04 & 0.04 & 0.04 \\
\hline & & $p$-value & $<0.05$ & $<0.05$ & $<0.05$ & $<0.05$ & $<0.05$ \\
\hline \multirow[t]{3}{*}{$\sigma^{2}$} & \multirow[t]{3}{*}{ Random intercept variability of the linear trend per stimulus } & Estimate & 5.71 & 3.14 & 2.10 & 1.71 & 1.86 \\
\hline & & SE & 1.32 & 0.76 & 0.54 & 0.45 & 0.49 \\
\hline & & $p$-value & $<0.001$ & $<0.001$ & $<0.001$ & $<0.001$ & $<0.001$ \\
\hline
\end{tabular}

SE, standard error; the within subject variability $\left(\sigma_{\varepsilon}^{2}\right)$ equals 1.54 (SE $=0.08, p<0.001$ ); the model explains $83 \%$ of the variance in the observed fear responses.

Table 2 (Model 3) Multilevel regression predicting the extinction of pain expectancy judgments to each stimulus and its association with inhibitory capacity.

\begin{tabular}{|c|c|c|c|c|c|c|c|}
\hline Effect & Description & & CS+ & GS1 & GS2 & GS3 & CS- \\
\hline \multirow[t]{3}{*}{$\mu$} & \multirow{3}{*}{$\begin{array}{l}\text { Estimated intercept of the linear trend (i.e. at } T=0 \text { ) per stimulus } \\
\text { for subjects with average levels of inhibition and with an } \\
\text { average random intercept value }\end{array}$} & Estimate & 7.83 & 5.75 & 3.60 & 2.57 & 2.37 \\
\hline & & SE & 0.31 & 0.31 & 0.27 & 0.26 & 0.27 \\
\hline & & $p$-value & $<0.0001$ & $<0.0001$ & $<0.0001$ & $<0.0001$ & $<0.0001$ \\
\hline \multirow[t]{3}{*}{$\beta_{\text {T }}$} & \multirow{3}{*}{$\begin{array}{l}\text { Slope of the linear trend per stimulus for subjects with an average } \\
\text { inhibition score (i.e. } Z_{i}^{\text {inhib }}=0 \text { ) }\end{array}$} & Estimate & 0.09 & -1.34 & -0.96 & -0.60 & -0.51 \\
\hline & & SE & 0.10 & 0.10 & 0.10 & 0.10 & 0.10 \\
\hline & & $p$-value & 0.93 & $<0.0001$ & $<0.0001$ & $<0.0001$ & $<0.0001$ \\
\hline \multirow[t]{3}{*}{$\beta_{\text {inhib }}$} & \multirow{3}{*}{$\begin{array}{l}\text { Increase in the intercept of the linear trend (i.e. at } T=0 \text { ) per } \\
\text { stimulus, due to an increase of one SD for the inhibition score }\end{array}$} & Estimate & -0.11 & -0.12 & -0.08 & -0.20 & -0.37 \\
\hline & & SE & 0.29 & 0.28 & 0.23 & 0.22 & 0.24 \\
\hline & & $p$-value & 0.70 & 0.68 & 0.75 & 0.37 & 0.12 \\
\hline \multirow[t]{3}{*}{$\beta_{\text {Txinhib }}$} & \multirow{3}{*}{$\begin{array}{l}\text { Interaction effect between the linear trend per stimulus and the } \\
\text { standardized inhibition score. This effect represents the change } \\
\text { in the slope of the linear trend if } Z_{i}^{\text {inhib }} \text { increases one standard } \\
\text { deviation (note: interactions are constrained to be equal across } \\
\text { stimuli) }\end{array}$} & Estimate & 0.11 & 0.11 & 0.11 & 0.11 & 0.11 \\
\hline & & SE & 0.05 & 0.05 & 0.05 & 0.05 & 0.05 \\
\hline & & $p$-value & $<0.05$ & $<0.05$ & $<0.05$ & $<0.05$ & $<0.05$ \\
\hline \multirow[t]{3}{*}{$\sigma^{2}$} & \multirow[t]{3}{*}{ Random intercept variability of the linear trend per stimulus } & Estimate & 2.86 & 2.62 & 1.62 & 1.52 & 1.69 \\
\hline & & SE & 0.74 & 0.69 & 0.47 & 0.45 & 0.49 \\
\hline & & $p$-value & $<0.0001$ & $<0.0001$ & $<0.0005$ & $<0.0005$ & $<0.0005$ \\
\hline
\end{tabular}

SE, standard error; the within subject variability $\left(\sigma_{\varepsilon}^{2}\right)$ equals 2.24 (SE $=0.12, p<0.001$ ); the model explains $81 \%$ of the variance in the observed fear responses.

We used a multilevel regression model to examine the differences between the PS+, CS+, and GSl (see Fig. 3). For the presence of a peak-shift effect (e.g. PS $+>$ CS $+>$ GS1), the difference between PS + and CS+ must be larger than the difference between CS+ and GS1. Therefore, GS1 was included in the analysis. For an area-shift, a mild version of the peak-shift effect, the PS+ elicits similar response magnitudes as the CS+, but larger response magnitudes compared to the GSI (e.g. PS $+=$ CS $+>$ GSl).
Results indicated no significant differences in the magnitude of the fear responses between the PS+ and the CS+ $\left(\beta^{(\mathrm{CS}+)}=-0.13, \quad t(90)=-0.43\right.$, $p=0.67$ ), while the magnitude of the fear responses to the PS+ was significantly greater than to the GSI $\left(\beta^{(\mathrm{GS} 1)}=-1.07, t(90)=-3.53, p<0.01\right)$. Similarly, pain expectancy judgments were higher for the PS+ than for the GSl $\left(\beta^{(\mathrm{GSl})}=-0.96, t(90)=-2.36\right.$, $p<0.05$ ), but no differences were observed between the CS+ and the PS+ $\left(\beta^{(\mathrm{CS}+)}=0.35, t(90)=0.86\right.$, 

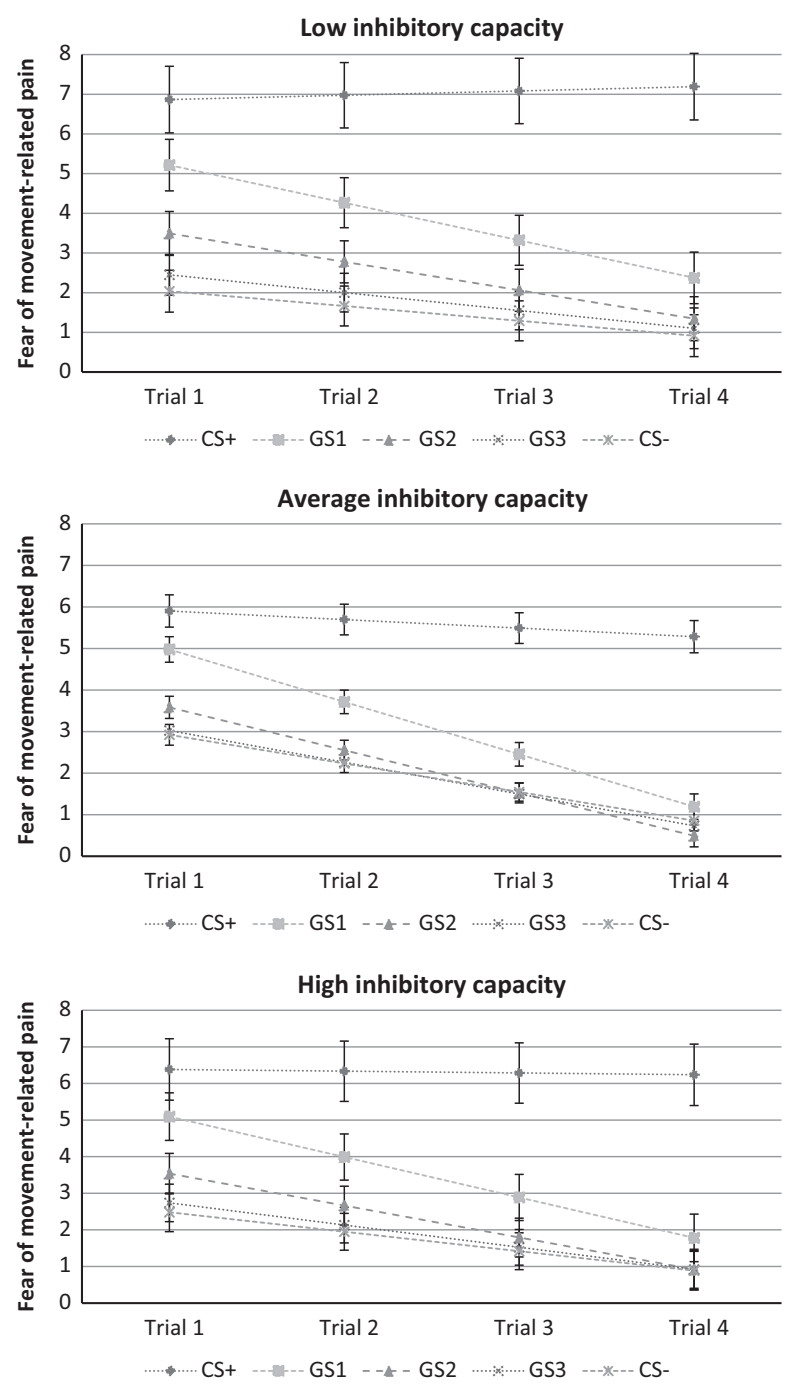

Figure 2 Extinction of fear ratings for low, average, and high inhibitory capacity. High inhibitory capacity refers to stop-signal reaction times -2 SD below the mean; low inhibitory capacity refers to stopsignal reaction times $+2 \mathrm{SD}$ above the mean on the stop-signal task.

$p=0.39$ ). In sum, there is no evidence for a peakshift, but rather for an area-shift. During area-shift, responses to either side of the CS+ elicit different response magnitudes, whereby stimuli situated on the CS - side elicit weaker responses than stimuli on the opposite side. We also tested whether executive function capacity affected the area-shift. In other words, we examined whether low executive function capacity leads to greater CRs to the PS+, which was not the case. Lastly, we examined whether low executive function capacity is associated with slower extinction of CRs to the PS+, which was also not the case.

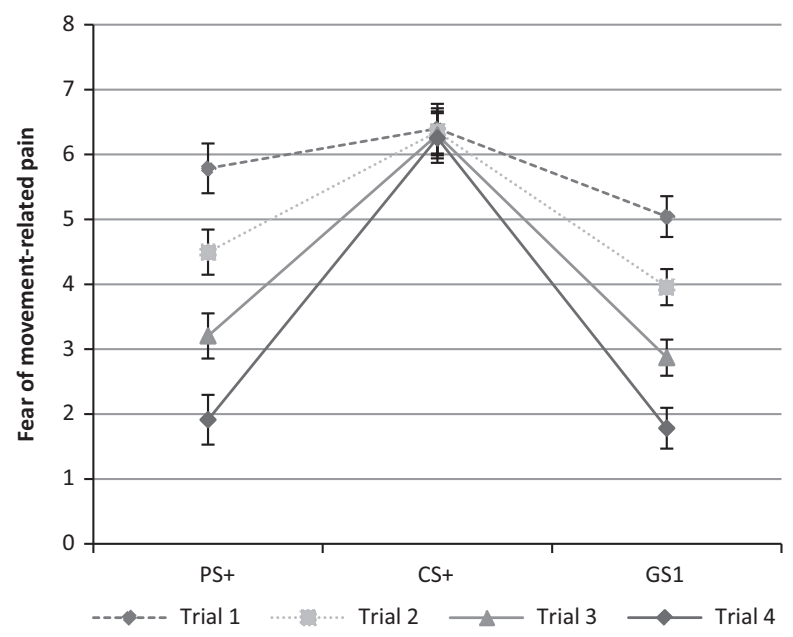

Figure 3 Extinction of peak-shift stimulus relative to CS+ and GS1. PS+, peak shift stimulus; CS+, movement predicting the onset of pain; GS1, generalization stimulus closest to the CS+.

\section{Discussion}

This study examined whether individual differences in executive function capacity contribute to generalization and extinction of generalization as well as peak-shift of conditioned fear of movement-related pain and expectancy. Replicating previous research, we observed that following successful differential fear acquisition, the strength of the fear response and pain expectancy to a novel unfamiliar movement was proportional to the resemblance of that movement with the original pain-provoking movement $(\mathrm{CS}+)$ and the movement predicting the absence of pain (CS-). The more closely the novel movement resembled the original pain-provoking movement, rather than the movement predicting the absence of pain, the greater the conditioned response (e.g., fear and pain expectancy) (Honig and Urcuioli, 1981; McLaren and Mackintosh, 2002; Lissek et al., 2008; Meulders et al., 2013; Geschwind et al., 2014). We extend previous knowledge in showing that low inhibitory capacity is associated with slower rates of extinction of generalized fear of movementrelated pain and pain expectancy. We also provided evidence suggesting that the peak of the conditioned fear response can extend, but does not shift, from the CS+ to the PS+, whereby the magnitude of the response to the PS+ is similar to the CS+, but greater than to the GS1, indicating an area-shift.

In our first hypothesis, we investigated whether participants with low executive function capacity displayed greater fear responses and pain expectancies to novel stimuli. While the data show that there 
is evidence of generalization of conditioned responses to novel stimuli, the absence of interactions between the strength of the generalized conditioned responses and executive function capacity, refutes our hypothesis. This finding is at odds with evidence suggesting a negative correlation between generalization and ability to block irrelevant information from entering working memory (Lenaert et al., 2016). Discrepancies may be due to the latter assessing generalization via a novel single continuous measure and employing a different measure of working memory.

In our second hypothesis, we investigated whether participants with low executive function capacity demonstrated slower extinction of generalized fear responses and pain expectancies. Low inhibitory capacity was associated with slower rates of extinction, implying the maintenance of conditioned fear of movement-related pain and pain expectancies in response to the GSs, despite their non-reinforcement. Inhibition refers to individuals' ability to refrain from dominant, prepotent, or automatic responses when necessary (Miyake et al., 2000). These results resemble theoretical models and clinical findings reporting reluctances to inhibit a conditioned response (Lissek et al., 2005; Meulders et al., 2015), suggesting that highly fearful individuals, despite awareness of CSpain-US contingencies, also respond fearfully to novel but safe GS movements that were never paired with the pain-US. Earlier work (Pappens et al., 2014), showed that high levels of resting heart rate variability, a proxy for autonomic inhibitory control, were associated with quicker fear extinction to a no longer reinforced CS+. The present study extends these findings in showing that high inhibitory capacity is also associated with quicker extinction of generalized fear responses and pain expectancy, hence responses to GSs, using an alternative measure of inhibitory capacity. Closely related, Flor and colleagues previously demonstrated that, relative to healthy controls, chronic back pain patients showed similar rates of acquisition, but slower extinction of verbal as well as cortical pain responses (Flor et al., 2002). In the light of the current findings and the results reported by Pappens and colleagues (Pappens et al., 2014), the findings by Flor and colleagues (Flor et al., 2002) could be the result of low inhibitory capacity, which has been reported among chronic pain patients (Berryman et al., 2014), impairing extinction. The current study confirms that low inhibitory capacity is not only associated with slower extinction of conditioned responses, but also with slower extinction of generalized conditioned responses.
These findings may have implications for the development of chronic pain-related disability, as the maintenance of higher levels of conditioned fear of movement-related pain and pain expectancy may lead to greater levels of pain over time, by promoting widespread activity avoidance. Avoidance in the context of pain is effective in reducing fear in the short term, rendering it attractive for repeated use. Nevertheless, repeated avoidance of cues that signal threat may exacerbate disability in the long term, due to its negative impact on social, work-related, and affective domains. These predictions warrant further examination in prospective designs.

In our third hypothesis, we investigated whether there was a peak-shift in fear responses and pain expectancies away from the original pain-provoking movement in participants with low executive function capacity compared to participants with high executive function capacity. When viewed on a continuum, PS+ and GSI are equidistant to CS+, while GSl is closer to CS- than CS+ and PS+ (continuum $=$ PS+, CS+, GS1, GS2, GS3, CS-, PS-). Building on the principles of generalization (Dunsmoor et al., 2011), PS+ should elicit greater responses than $\mathrm{CS}+(\mathrm{PS}+>\mathrm{CS}+>\mathrm{GSl})$, as it lies outside the $\mathrm{CS}+\mathrm{I}-$ continuum to the CS+ side (Blough, 1975; Honig and Urcuioli, 1981; Pearce, 1987; McLaren and Mackintosh, 2002; Ghirlanda and Enquist, 2003; Struyf et al., 2014). The results show no evidence for the presence of such a peak-shift, as responses to PS+ were not greater than to CS+. In fact, the analysis suggests that significantly greater pain expectancy and fear of movement-related pain responses were found in response to the PS+ as compared to the GS1, while the PS+ and the CS+ elicited equal response magnitudes ( $\mathrm{PS}+=\mathrm{CS}+>\mathrm{GS} 1$ ), thus suggesting area-shift (Thomas et al., 1991; Spetch et al., 2004; ten Cate and Rowe, 2007). During area-shift, commensurable stimuli to either side of the CS+ elicit different response magnitudes, whereby stimuli situated on the CS- side elicit weaker responses than stimuli on the opposite side. Consequently, area-shift requires only one contrast (PS+ > GS1) to be statistically significant. Evidence found in favor of area-shift must be considered a secondary finding, as our hypotheses specified testing for peak-shift. The findings may have implications for pain, as certain novel movements can elicit peak levels of fear and pain expectancy although they have never been paired with pain. The activation of brain areas responsible for pain hyperalgesia associated with high levels of conditioned fear of movement-related pain and pain expectancy may aggravate the pain 
experience of novel movements and elicit even greater fear and pain over time (Sawamoto et al., 2000; Koyama et al., 2005; Keltner et al., 2006).

Analyses revealed that updating and switching capacities were associated with individuals' selected pain-US intensity during the calibration phase. The notion of updating has often been described as a measure reflecting working memory capacity (Miyake et al., 2000), which has shown to be impaired among chronic pain patients (Berryman et al., 2013; Attridge et al., 2015). It is unclear how updating and pain-US intensity interact, but it may be possible that low updating capacity is associated with a heightened sensitivity to pain due to decreased attentional control of pain (Legrain et al., 2011). Further analyses of the pain ratings obtained after each phase might bring clarity to the sensitivity hypothesis, but exceed the scope of this paper. Conversely, high switching capacity is associated with selecting lower pain-US intensities, for which we have no apparent explanation. Both findings are at odds with previous research, reporting associations exclusively between the inhibition facet of executive function and pain intensity ratings (Oosterman et al., 2010) or the complete absence of a relationship (Verhoeven et al., 2011). Reasons for such diverse findings may be rooted in the nature of the tasks used to measure executive function, and/or the pain-induction methods, despite our attempts to mitigate against lack of construct validity by using tasks that primarily implicate updating and shifting ability (Miyake et al., 2000).

Further prudence is invited when interpreting the results pertaining to executive function. As a rather diffuse concept, there is little consistency as to the processes comprising executive function, and the proposed facets may not be completely independent (Miyake et al., 2000; Berryman et al., 2013, 2014). Furthermore, there is ongoing debate regarding the construct validity of executive function tests (Miyake et al., 2000). Berryman and colleagues (Berryman et al., 2013, 2014) reported inconsistencies in findings relating to executive function depending on the choice of test and not the facet measured. Additionally, most tests suffer from 'task impurity' (Miyake et al., 2000); hence, low scores on measures of executive function might not represent impairments in executive function, but impairments in other cognitive processes also involved in the execution of the task. In light of such inconsistencies, future studies should focus on developing a 'standardized test battery', which might improve comparability between studies and increase reliability of future results.
Further caution is needed when interpreting these findings. To maximize homogeneity of the study sample, a number of exclusion criteria were used, limiting the generalizability of findings to the general population. The great number of statistical tests conducted may increase the risk of false positives and warrant replication. The paradigm included paininduction in a laboratory setting. This may not be fully representative of the context in which individuals usually experience pain. Therefore, ecological validity of the results may be limited. In addition, healthy undergraduates differ from individuals with chronic pain on a number of demographic (e.g., age, education) and health status variables (e.g., co-morbidities). As such, the sample includes few extreme values on the executive function facets, which limits the applicability of present study findings to chronic pain patients. Nevertheless, and despite this limitation, robust and significant effects were found in this sample.

In spite of these limitations, our findings show that the maximum of fear responding and pain expectancy judgments extended from the movement predicting the onset of pain to include another novel but similar movement. Furthermore, we found evidence that low inhibitory capacity is associated with slower extinction of generalized fear of movement-related pain and pain expectancy judgments. Enhancing inhibitory control might therefore be a valuable approach to treat or prevent pain-related suffering and disability, which can be done with several techniques, of which mere practice (Davidson et al., 2003), and vagus nerve stimulation (Pena et al., 2014) might be interesting candidates. However, more research in this area is highly needed.

\section{Note}

${ }^{1}$ Startle measures were collected; however, due to the absence of differential startle amplitudes between CS+ and CS- (no fear acquisition), the description of the startle measure and all related aspects was omitted. For detailed information on the startlerelated procedure used in this study, please see Meulders et al. (2011).

\section{References}

Attridge, N., Noonan, D., Eccleston, C., Keogh, E. (2015). The disruptive effects of pain on n-back task performance in a large general population sample. Pain 156 (10), 1885-1891.

Berryman, C., Stanton, T.R., Jane Bowering, K., Tabor, A., McFarlane, A., Moseley, G.L. (2013). Evidence for working memory deficits in 
chronic pain: A systematic review and meta-analysis. Pain 154, 11811196. doi:10.1016/j.pain.2013.03.002.

Berryman, C., Stanton, T.R., Bowering, K.J., Tabor, A., McFarlane, A., Moseley, G.L. (2014). Do people with chronic pain have impaired executive function? A meta-analytical review. Clin Psychol Rev 34, 563-579. doi:10.1016/j.cpr.2014.08.003.

Blough, D.S. (1975). Steady-state data and a quantitative model of operant generalization and discrimination. J Exp Psychol 104, 3-21. doi:10.1037/0097-7403.1.1.3.

Boddez, Y., Baeyens, F., Luyten, L., Vansteenwegen, D., Hermans, D. Beckers, T. (2013). Rating data are underrated: Validity of US expectancy in human fear conditioning. J Behav Ther Exp Psychiatry 44, 201-206. doi:10.1016/j.jbtep.2012.08.003.

Bradley, M.M., Lang, P.J. (1994). Measuring emotion: The selfassessment manikin and the semantic differential. J Behav Ther Exp Psychiatry 25, 49-59.

ten Cate, C., Rowe, C. (2007). Biases in signal evolution: Learning makes a difference. Trends Ecol Evol 22, 380-387. doi:10.1016/j.tree. 2007.03.006.

Davidson, D.J., Zacks, R.T., Williams, C.C. (2003). Stroop interference, practice, and aging. Neuropsychol Dev Cogn B Aging Neuropsychol Cogn 10, 85-98. doi:10.1076/anec.10.2.85.14463.

Dunsmoor, J.E., Mitroff, S.R., Labar, K.S. (2009). Generalization of conditioned fear along a dimension of increasing fear intensity. Learn Memory 16, 460-469. doi:10.1101/Lm.1431609.

Dunsmoor, J.E., Prince, S.E., Murty, V.P., Kragel, P.A., LaBar, K.S. (2011). Neurobehavioral mechanisms of human fear generalization. NeuroImage 55, 1878-1888. doi:10.1016/j.neuroimage. 2011.01 .041 .

Flor, H., Knost, B., Birbaumer, N. (2002). The role of operant conditioning in chronic pain: An experimental investigation. Pain 95, $111-118$.

Geschwind, N., Meulders, M., Peters, M.L., Vlaeyen, J.W., Meulders, A. (2014). Can experimentally induced positive affect attenuate generalization of fear of movement-related pain? J Pain 16(3), 258269.

Ghirlanda, S., Enquist, M. (2003). A century of generalization. Anim Behav 66, 15-36.

Grant, D.A., Berg, E.A. (1948). A behavioral analysis of degree of reinforcement and ease of shifting to new responses in a Weigl-type card-sorting problem. J Exp Psychol 38, 404-411.

Honig, W.K., Urcuioli, P.J. (1981). The Legacy of Guttman and Kalish (1956) - 25 years of research on stimulus-generalization. J Exp Anal Behav 36, 405-445. doi:10.1901/jeab.1981.36-405.

Keltner, J.R., Furst, A., Fan, C., Redfern, R., Inglis, B., Fields, H.L. (2006). Isolating the modulatory effect of expectation on pain transmission: A functional magnetic resonance imaging study. J Neurosci 26, 4437-4443. doi:10.1523/JNEUROSCI.4463-05. 2006.

Koyama, T., McHaffie, J.G., Laurienti, P.J., Coghill, R.C. (2005). The subjective experience of pain: Where expectations become reality. Proc Natl Acad Sci USA 102, 12950-12955. doi:10.1073/pnas. 0408576102 .

Lappin, J.S., Eriksen, C.W. (1966). Use of a delayed signal to stop a visual reaction-time response. J Exp Psychol 72, 805. doi:10.1037/ H002 1266.

Legrain, V., Crombez, G., Verhoeven, K., Mouraux, A. (2011). The role of working memory in the attentional control of pain. Pain 152, 453459. doi:10.1016/j.pain.2010.11.024.

Lenaert, B., van de Ven, V., Kaas, A.L., Vlaeyen, J.W. (2016). Generalization on the basis of prior experience is predicted by individual differences in working memory. Behav Ther 47, 130-140. doi:10.1016/j.beth.2015.10.001.

Lissek, S., Powers, A.S., McClure, E.B., Phelps, E.A., Woldehawariat, G., Grillon, C., Pine, D.S. (2005). Classical fear conditioning in the anxiety disorders: A meta-analysis. Behav Res Ther 43, 1391-1424. doi:10.1016/j.brat.2004.10.007.

Lissek, S., Biggs, A.L., Rabin, S.J., Cornwell, B.R., Alvarez, R.P., Pine, D.S., Grillon, C. (2008). Generalization of conditioned fear- potentiated startle in humans: Experimental validation and clinical relevance. Behav Res Ther 46, 678-687. doi:10.1016/j.brat.2008.02. 005 .

McLaren, I.P., Mackintosh, N.J. (2002). Associative learning and elemental representation: II. Generalization and discrimination. Anim Learn Behav 30, 177-200. doi:10.3758/Bf03192828.

McNeil, D.W., Rainwater, A.J. 3rd (1998). Development of the fear of pain questionnaire-III. J Behav Med 21, 389-410.

Meulders, A., Vansteenwegen, D., Vlaeyen, J.W. (2011). The acquisition of fear of movement-related pain and associative learning: A novel pain-relevant human fear conditioning paradigm. Pain 152, 2460-2469. doi:10.1016/j.pain.2011.05.015.

Meulders, A., Vandebroek, N., Vervliet, B., Vlaeyen, J.W. (2013). Generalization gradients in cued and contextual pain-related fear: An experimental study in healthy participants. Front Hum Neurosci 7, 345. doi:10.3389/fnhum.2013.00345.

Meulders, A., Jans, A., Vlaeyen, J.W. (2015). Differences in painrelated fear acquisition and generalization: An experimental study comparing patients with fibromyalgia and healthy controls. Pain 156, 108-122. doi:10.1016/j.pain.0000000000000016.

Miyake, A., Friedman, N.P., Emerson, M.J., Witzki, A.H., Howerter, A., Wager, T.D. (2000). The unity and diversity of executive functions and their contributions to complex "Frontal Lobe" tasks: A latent variable analysis. Cogn Psychol 41, 49-100. doi:10.1006/cogp.1999. 0734 .

Oosterman, J.M., Dijkerman, H.C., Kessels, R.P.C., Scherder, E.J.A. (2010). A unique association between cognitive inhibition and pain sensitivity in healthy participants. Eur J Pain 14, 1046-1050. doi:10. 1016/j.ejpain.2010.04.004.

Pappens, M., Schroijen, M., Sutterlin, S., Smets, E., Van den Bergh, O., Thayer, J.F., Van Diest, I. (2014). Resting heart rate variability predicts safety learning and fear extinction in an interoceptive fear conditioning paradigm. PLOS ONE 9, e105054. doi:10.1371/journal. pone.0105054.

Pavlov, I.P., Anrep, G.V. (1927). Conditioned Reflexes; an Investigation of the Physiological Activity of the Cerebral Cortex. (London: Oxford University Press; Humphrey Milford).

Pearce, J.M. (1987). A model for stimulus generalization in Pavlovian conditioning. Psychol Rev 94, 61-73.

Pena, D.F., Childs, J.E., Willett, S., Vital, A., McIntyre, C.K., Kroener, S. (2014). Vagus nerve stimulation enhances extinction of conditioned fear and modulates plasticity in the pathway from the ventromedial prefrontal cortex to the amygdala. Front Behav Neurosci 8, ARTN 327. doi:10.3389/fnbeh.2014.00327.

Rao, S.M., Hammeke, T.A., Speech, T.J. (1987). Wisconsin Card Sorting Test performance in relapsing-remitting and chronic-progressive multiple sclerosis. J Consult Clin Psychol 55, 263-265.

Rescorla, R.A. (1969). Conditioned inhibition of fear resulting from negative CS- US contingencies. J Comp Physiol Psychol 67, 504509.

Sawamoto, N., Honda, M., Okada, T., Hanakawa, T., Kanda, M., Fukuyama, H., Konishi, J., Shibasaki, H. (2000). Expectation of pain enhances responses to nonpainful somatosensory stimulation in the anterior cingulate cortex and parietal operculum/posterior insula: An event-related functional magnetic resonance imaging study. $J$ Neurosci 20, 7438-7445.

Spetch, M.L., Cheng, K., Clifford, C.W.G. (2004). Peak shift but not range effects in recognition of faces. Learn Motiv 35, 221-241. doi:10. 1016/j.lmot.2003.11.001.

Spruyt, A., Clarysse, J., Vansteenwegen, D., Baeyens, F., Hermans, D. (2010). Affect 4.0 a free software package for implementing psychological and psychophysiological experiments. Exp Psychol 57, 36-45. doi:10.1027/1618-3169/A000005.

Struyf, D., Iberico, C., Vervliet, B. (2014). Increasing predictive estimations without further learning: The peak-shift effect. Exp Psychol 61, 134-141. doi:10.1027/1618-3169/a000233.

Sullivan, M.J.L., Bishop, S.R., Pivik, J. (1995). The Pain Catastrophizing Scale: Development and validation. Psychol Assessment 7, 524-532. doi:10.1037/1040-3590.7.4.524. 
Thomas, D.R., Mood, K., Morrison, S., Wiertelak, E. (1991). Peak shift revisited: A test of alternative interpretations. J Exp Psychol Anim Behav Process 17, 130-140.

Turner, M.L., Engle, R.W. (1989). Is working memory capacity task dependent. J Mem Lang 28, 127-154. doi:10.1016/0749-596x(89) 90040-5.

Verbeke, G., Molenberghs, G. (2000). Linear Mixed Models for Longitudinal Data. (New York: Springer).

Verbruggen, F., Logan, G.D. (2008). Response inhibition in the stopsignal paradigm. Trends Cogn Sci 12, 418-424. doi:10.1016/j.tics.2008. 07.005 .

Verhoeven, K., Van Damme, S., Eccleston, C., Van Ryckeghem, D.M.L., Legrain, V., Crombez, G. (2011). Distraction from pain and executive functioning: An experimental investigation of the role of inhibition, task switching and working memory. Eur J Pain 15, 866-873. doi:10. 1016/j.ejpain.2011.01.009.

Vervliet, B., Baeyens, F., Van den Bergh, O., Hermans, D. (2013). Extinction, generalization, and return of fear: A critical review of renewal research in humans. Biol Psychol 92, 51-58. doi:10.1016/j. biopsycho.2012.01.006.

Vince, M.A. (1948). The intermittency of control movements and the psychological refractory period. Br J Psychol Gen Sect 38, 149157.

Vlaeyen, J.W., Kole-Snijders, A.M., Boeren, R.G., van Eek, H. (1995). Fear of movement/(re)injury in chronic low back pain and its relation to behavioral performance. Pain 62, 363-372.

\section{Supporting Information}

Additional Supporting Information may be found online in the supporting information tab for this article:

Figure S1. Peak-shift effect illustration.

Figure S2. Self-reported fear of movement-related pain during acquisition (Acq $1-3$ ) and transfer of acquisition (Tr 1 ).
Table S1. Conceptual overview.

Table S2. Sample characteristics.

Table S3. Correlations between executive function tasks and pain-US intensity.

Table S4. Overview of number of participants scoring within a certain range of standardized predictor variables.

Table S5. (Model 2) Multilevel regressions predicting the generalization of state fear of movement-related pain and its association with executive function capacity.

Table S6. (Model 2) Multilevel regressions predicting the generalization of pain expectancy judgments and their association with executive function capacity.

Table S7. (Model 3) Multilevel regression predicting the extinction of fear responses to each stimulus and its association with switching capacity.

Table S8. (Model 3) Multilevel regression predicting the extinction of pain expectancy judgments to each stimulus and its association with switching capacity.

Table S9. (Model 3) Multilevel regression predicting the extinction of fear responses to each stimulus and its association with updating capacity.

Table S10. (Model 3) Multilevel regression predicting the extinction of pain expectancy judgments to each stimulus and its association with updating capacity.

Table S11. (Model 1) Multilevel regression predicting the acquisition of fear responses to CS+ and CS-

Appendix S1. Supporting information - Model descriptions.

Appendix S2. Supporting information - manipulation checks. 